\title{
Typical and extremely hot summer conditions trigger a diverse response of phenolic metabolism in apple peel
}

\author{
A. Cebulj, M. Mikulic-Petkovsek, A. Slatnar, K. Eler and R. Veberič \\ Department of Agronomy, Biotechnical Faculty, University of Ljubljana, Ljubljana, Slovenia
}

\begin{abstract}
Summary
The reaction of two apple cultivars ('Braeburn' and 'Golden Delicious') on dissimilar temperature conditions (SD1 - extremely high temperatures and SD2 - regular summer temperatures) was evaluated in terms of their phenolic accumulation. Total and photosynthetically active radiation as well as air and fruit temperatures were higher on SD1. Fruit temperature was approx. $10^{\circ} \mathrm{C}$ higher on SD1 in comparison to SD2. Significant differences in phenolic content levels were detected between the two sampling days. Higher amounts of hydroxycinnamic acids, flavonols, flavanols and dihydrochalcones were measured in sunburned (SB) and healthy sun exposed (HS) 'Golden Delicious' apples on SD1 compared to SD2. The differences in phenolic content were less prominent in 'Braeburn' peel sampled on both sampling dates. Differences in phenolic accumulation were also determined between morning ( $7 \mathrm{am}$ ) and afternoon (1 pm) samplings but the changes were less uniform and only significant in 'Braeburn' HS peel and 'Golden Delicious' SB peel. No changes in phenolic content levels have been detected in apples inside the tree crown on different sampling dates and hours of the day.
\end{abstract}

Keywords

Slovenia, Malus domestica Borkh., dihydrochalcones, flavanols, flavonols, hydroxycinnamic acids, sunburn

\section{Introduction}

Plants have to withstand different, sometimes extreme, weather conditions as they cannot move and evade them. Therefore, they have developed numerous approaches to protect themselves on the spot. A typical defence mechanism is the biosynthesis of phenolic compounds, which protect plants against various types of stresses caused by adverse environmental conditions, such as high and low temperature, drought, alkalinity, salinity, UV stress and pathogen infection (Akula and Ravishankar, 2011; Treutter, 2001).

Enhanced synthesis and accumulation of phenolic compounds are not always sufficient and irreversible damage of plant tissue frequently occurs. Sunburn is a disorder of apple and other fruit species caused by excess solar radiation. Felicetti and Schrader (2009) classified three different types of sunburn: sunburn necrosis, sunburn browning, and photo-oxidative sunburn. Sunburn browning is the prevailing type of apple fruit sunburn caused by the combination of elevated fruit temperatures and high solar radiation (Racsko and Schrader, 2012). Several studies have focused on

\section{Significance of this study}

What is already known on this subject?

- Apple fruits defend themselves against numerous types of stresses with various mechanisms, among which also biosynthesis of phenolic compounds.

What are the new findings?

- Phenolic content of apples varied between the two diverse sampling days and moderate fluctuations were also detected in a single day.

What is the expected impact on horticulture?

- This study is a good basis for further research on the rapid response of apple fruits to stress situations via phenolic accumulation.

pigment and phenolic metabolite concentrations associated with sunburn browning (Felicetti and Schrader, 2009; Merzlyak et al., 2002; Yuri et al., 2010; Zupan et al., 2014) and the degree of fruit damage (Felicetti and Schrader, 2008). The reports unanimously portray higher flavonol, hydroxycinnamic acid and dihydrochalcone content, lower anthocyanin and chlorophyll content and higher peroxidase activity in sunburned apples in comparison to non-sunburned or even shaded apple fruits. A distinct pattern of total phenolic content (TPC) has also been reported. Sun-exposed apples (sunburned and healthy sun-exposed fruit) generally contain higher TPC in comparison to shaded parts of apple fruit and apples inside the tree canopy. Even though the content of phenolic compounds varies during fruit development, regardless of stress (Awad et al., 2001), the analysis of enzymes proves the unfavourable conditions. Li et al. (2013) confirmed the up-regulation of many enzymes involved in phenylpropanoid pathway in sun-exposed apple peel, which confirms the hypothesis of up-regulation of the entire phenylpropanoid pathway in these diverse conditions. But how fast is the response of plants to stress situations? Changes in phenolic content levels were assessed after induced mechanical injury of apple leaves and Slatnar et al. (2013) reported higher TPC in damaged 'Golden Delicious' leaves a day after the injury. The monitoring of diurnal variation of total phenols in some Hypericum species has exposed the highest phenolic content in leaves at noon (Ayan et al., 2008). Therefore, the aim of the present study was to evaluate the response of apple fruits to different environmental factors by monitoring the phenolic accumulation on two different summer days: a day with extreme weather conditions favourable for sunburn occurrence and a typical day with average summer temperatures and solar radiation. Three different types of 
apple fruit were sampled: sunburned fruit, healthy sun-exposed fruit, and healthy fruit inside the tree crown at two different day periods (morning and afternoon) in order to determine the response of apple fruit to stress situation via phenolic accumulation.

\section{Materials and methods}

\section{Plant material and measurements in the orchard}

Two apple cultivars, 'Braeburn' and 'Golden Delicious', were included in the experiment located at the experimental orchard of Biotechnical faculty in Ljubljana (latitude $46.05^{\circ} \mathrm{N}$, longitude $11.47^{\circ} \mathrm{E}$, altitude $289 \mathrm{~m}$ ). Apple fruits were harvested on two different dates in August 2013. The first sampling was conducted on August $8^{\text {th }}$, when the temperatures were as high as $40^{\circ} \mathrm{C}$. The second sampling was on August $21^{\text {st }}$, when temperatures were considerably lower (maximum daily temperature $26^{\circ} \mathrm{C}$ ). Both days were clear and sunny and on each occasion, samples were collected at $7 \mathrm{am}$ and at $1 \mathrm{pm}$. Three treatments were investigated corresponding to the fruit sunburn damage and position within a tree: (SB), sunburned apples; (HS), apples with no visible damage on the surface of fruits from the outside of the tree canopy; and (IC), apples from the inside of the tree canopy. Each treatment consisted of 24 fruits from 12 apple trees. After harvest, apples were immediately transported to the laboratory, and the peels (about $2 \mathrm{~mm}$ thick) were immersed into liquid nitrogen and stored at $-80^{\circ} \mathrm{C}$ until further analysis.

Air temperature, apple fruit temperature, total radiation and PAR were measured in the orchard each time before sampling. Air temperature was recorded at the automatic weather station situated in the faculty experimental field at $2 \mathrm{~m}$ aboveground. Apple fruit temperature was measured with a portable digital waterproof thermometer P 300 (Dostmann Electronic GmbH, Germany), with the probe inserted approx. $6 \mathrm{~mm}$ into the fruit. Temperature was measured on ten apples at each sampling and the fruits were later used for phenolic analyses, but the punctured part of the skin and mesocarp were excluded. Total radiation and PAR were measured using a Li 1000 Datalogger (LI-COR, USA) in ten repetitions at each sampling. The measurements in the orchard were recorded between the rows one meter above the ground and the sensors were placed parallel to the ground. Radiation was also measured above the sunburned fruits (the sensor was placed directly above the sunburn) and inside the tree crown (the sensors were parallel to the ground).

\section{Extraction and determination of individual phenolic compounds}

Frozen apple peels were ground in a mortar chilled with liquid nitrogen to a fine powder and $0.5 \mathrm{~g}$ of sample was extracted with $6 \mathrm{~mL}$ of methanol (Sigma-Aldrich) containing $3 \%(\mathrm{v} / \mathrm{v}$ ) formic acid (Fluka). Further extraction procedures and HPLC-MS ${ }^{2}$ analysis were performed as described by Zupan et al. (2013). The results were presented in $\mathrm{mg} \mathrm{kg}^{-1} \mathrm{FW}$.

Twenty-eight phenolic compounds from four phenolic groups were quantified in 'Braeburn' and 'Golden Delicious' apple skin: hydroxycinnamic acids ( $p$-coumaric acid glycoside 1 and 2, trans-5-O-caffeoylquinic acid, 4-caffeoylquinic acid, cis-5-O-caffeoylquinic acid, sinapic acid glycoside and 4-O-p-coumaroylquinic acid), flavanols (catechin, epicatechin, procyanidin B1 and B2, procyanidin dimer 1 and 2, procyanidin trimer 1-4 and procyanidin tetramer), dihydrochalcones (3-hydroxy-phloretin-2'-O-xyloglucoside, phloretin-2'-O-xylosylglucoside and phloretin-2-O-glucoside (phloridzin)) and flavonols (Quercetin-3-O-rutinoside, Quercetin-3-O-galactoside, Quercetin-3-O-glucoside, Quercetin-3-O-xyloside, Quercetin-3-O-arabinopyranoside, Quercetin-3-O-arabinofuranoside and Quercetin-3-O-rhamnoside) (Tables 3 and 4).

\section{Statistics}

Peels of three fruits were combined into one sample, resulting in eight replicate samples for each treatment (in total, $4 \times 3 \times 8=96$ samples for each apple variety). For temperature measurements and solar radiation a one-way analysis of variance (ANOVA) and LSD test were used to determine the difference among treatments (SB, HS and IC). Data were analysed with the Statgraphics Centurion program (Manugistics Inc., Maryland, USA).

TABLE 3. The content of different phenolic groups (mean and standard error (SE) in $\mathrm{mg} \mathrm{kg}^{-1} \mathrm{FW}$ ) in 'Braeburn' peel of sunburned fruit, healthy sun exposed fruit and fruit inside the tree crown in the morning and afternoon on two sampling dates.

\begin{tabular}{|c|c|c|c|c|c|c|c|c|}
\hline & \multicolumn{4}{|c|}{ Sampling date 1} & \multicolumn{4}{|c|}{ Sampling date 2} \\
\hline & \multicolumn{2}{|c|}{ Morning } & \multicolumn{2}{|c|}{ Afternoon } & \multicolumn{2}{|c|}{ Morning } & \multicolumn{2}{|c|}{ Afternoon } \\
\hline & Mean & SE & Mean & SE & Mean & SE & Mean & SE \\
\hline \multicolumn{9}{|l|}{ Sunburn } \\
\hline Hydroxycinnamic acids & 217 & 6 & 236 & 10 & 199 & 5 & 220 & 7 \\
\hline Flavanols & 727 & 17 & 818 & 40 & 610 & 14 & 684 & 30 \\
\hline Dihydrochalcones & 177 & 5 & 173 & 9 & 115 & 1 & 146 & 3 \\
\hline Flavonols & 2062 & 55 & 2277 & 186 & 1409 & 55 & 1904 & 95 \\
\hline \multicolumn{9}{|l|}{ Healthy sun exposed } \\
\hline Hydroxycinnamic acids & 185 & 3 & 176 & 2 & 121 & 3 & 197 & 3 \\
\hline Flavanols & 940 & 21 & 1002 & 35 & 588 & 14 & 1003 & 26 \\
\hline Dihydrochalcones & 122 & 3 & 114 & 3 & 75 & 2 & 116 & 3 \\
\hline Flavonols & 747 & 28 & 734 & 38 & 582 & 39 & 1235 & 67 \\
\hline \multicolumn{9}{|l|}{ Inside the crown } \\
\hline Hydroxycinnamic acids & 165 & 3 & 132 & 2 & 150 & 2 & 139 & 1 \\
\hline Flavanols & 1010 & 24 & 975 & 15 & 1073 & 18 & 986 & 13 \\
\hline Dihydrochalcones & 107 & 2 & 108 & 1 & 95 & 1 & 97 & 2 \\
\hline Flavonols & 148 & 7 & 107 & 4 & 159 & 6 & 235 & 11 \\
\hline
\end{tabular}


TABLE 4. The content of different phenolic groups (mean and standard error (SE) in $\mathrm{mg} \mathrm{kg}^{-1} \mathrm{FW}$ ) in 'Golden Delicious' peel of sunburned fruit, healthy sun exposed fruit and fruit inside the tree crown in the morning and afternoon on two sampling dates.

\begin{tabular}{|c|c|c|c|c|c|c|c|c|}
\hline & \multicolumn{4}{|c|}{ Sampling date 1} & \multicolumn{4}{|c|}{ Sampling date 2} \\
\hline & \multicolumn{2}{|c|}{ Morning } & \multicolumn{2}{|c|}{ Afternoon } & \multicolumn{2}{|c|}{ Morning } & \multicolumn{2}{|c|}{ Afternoon } \\
\hline & Mean & SE & Mean & SE & Mean & SE & Mean & SE \\
\hline \multicolumn{9}{|l|}{ Sunburn } \\
\hline Hydroxycinnamic acids & 391 & 12 & 419 & 7 & 254 & 6 & 365 & 11 \\
\hline Flavanols & 1028 & 34 & 1181 & 16 & 465 & 12 & 764 & 17 \\
\hline Dihydrochalcones & 192 & 7 & 246 & 6 & 107 & 4 & 166 & 7 \\
\hline Flavonols & 2763 & 211 & 2748 & 69 & 1435 & 50 & 2272 & 144 \\
\hline \multicolumn{9}{|l|}{ Healthy sun exposed } \\
\hline Hydroxycinnamic acids & 295 & 9 & 289 & 5 & 223 & 6 & 251 & 5 \\
\hline Flavanols & 1115 & 30 & 1183 & 28 & 654 & 16 & 781 & 18 \\
\hline Dihydrochalcones & 205 & 10 & 182 & 6 & 108 & 5 & 140 & 6 \\
\hline Flavonols & 2489 & 244 & 1649 & 84 & 1108 & 62 & 1604 & 86 \\
\hline \multicolumn{9}{|l|}{ Inside the crown } \\
\hline Hydroxycinnamic acids & 264 & 5 & 211 & 2 & 186 & 5 & 208 & 4 \\
\hline Flavanols & 1150 & 25 & 984 & 13 & 592 & 21 & 700 & 18 \\
\hline Dihydrochalcones & 119 & 2 & 119 & 2 & 75 & 2 & 81 & 2 \\
\hline Flavonols & 501 & 19 & 426 & 11 & 254 & 8 & 265 & 6 \\
\hline
\end{tabular}

Data on phenolic compounds were analysed in two steps. First, univariate tests (factorial ANOVA) were performed for each compound and each apple variety separately with sampling date, hour of sampling and groups of fruits as factors. Prior to ANOVA homogeneity of variances within treatments was investigated graphically and log transformation was used if necessary. After ANOVA several planned contrasts at $\alpha=0.05$ were used to test for the effects of sampling date and hour of sampling for each phenolic compound separately.

Second, multivariate approach, namely principal component analysis (PCA), was used to compare joint phenolic composition of groups of fruits, sampling dates, hour of sampling and varieties. The correlation matrix instead of the raw values was used for PCA to account for the differences in measurement scales of different chemical parameters. All analyses were performed in $\mathrm{R}$ environment ( $\mathrm{R}$ Core Team, 2013).

\section{Results}

Two dissimilar days were chosen for the experiment: a day with the highest temperature in 2013 (August $8^{\text {th }}$ ) and a typical summer day (August $21^{\text {st }}$ ). Average long-term $\mathrm{Au}$ - gust temperature for Ljubljana is $20.6^{\circ} \mathrm{C}$ and average maximum temperature is $26.7^{\circ} \mathrm{C}$ (Slovenian Environment Agency). Mean temperatures for August 2013 were $29.6^{\circ} \mathrm{C}$ on the first sampling day (SD1) and $21.0^{\circ} \mathrm{C}$ on the second sampling day (SD2). Maximum temperature reached $40.2^{\circ} \mathrm{C}$ on SD1 and was considerably lower $\left(25.8^{\circ} \mathrm{C}\right)$ on SD2.

In addition to air temperatures, photosynthetically active radiation (PAR) and total radiation were recorded in the orchard and directly above the fruit. Significant differences in PAR were detected between the two sampling dates: $1746 \pm 43 \mu \mathrm{mol} \mathrm{s}^{-1} \mathrm{~m}^{-2}$ PAR was measured in the orchard on August $8^{\text {th }}$ and $1575 \pm 25 \mu \mathrm{mol} \mathrm{s}{ }^{-1} \mathrm{~m}^{-2}$ on August $21^{\text {st }}$ at $1 \mathrm{pm}$. Correspondingly, higher total radiation was measured on $\mathrm{Au}$ gust $8^{\text {th }}\left(943 \pm 26 \mathrm{~W} \mathrm{~m}^{-2}\right)$ compared to August $21^{\text {st }}(873.7 \pm 25$ $\mathrm{W} \mathrm{m}^{-2}$ ). Radiation was also recorded directly above the sunburned apples and inside the tree crown (Table 1). Significant differences in radiation between the two sampling positions (SB and IC) were already visible in morning recordings on both sampling days. However, differences in radiation between SB and IC measurements were substantial at one pm.

Ambient air temperature and radiation affected the temperature of apple fruit. Fruit temperatures were very similar

TABLE 1. Photosynthetically active radiation (PAR; $\mu \mathrm{mol} \mathrm{s} \mathrm{s}^{-1} \mathrm{~m}^{-2}$ ) and total radiation $\left(\mathrm{W} \mathrm{m}^{-2}\right.$ ) on sampling dates 1 (August $8^{\text {th }}$, 2013) and 2 (August 21 $1^{\text {st }}$, 2013). Morning (M) and afternoon (A) values were recorded near the sunburned surface (SB) and inside the tree crown (IC).

\begin{tabular}{|c|c|c|c|c|c|}
\hline & & \multicolumn{2}{|c|}{ PAR } & \multicolumn{2}{|c|}{ Total radiation } \\
\hline & & SB & IC & SB & IC \\
\hline \multirow{2}{*}{ August 8th, 2013} & $M$ & $65.7 \pm 6.7 b^{a}$ & $19.5 \pm 2.8 \mathrm{a}$ & $36.3 \pm 3.7 b$ & $24.3 \pm 3.7 \mathrm{a}$ \\
\hline & $\mathrm{A}$ & $1345.4 \pm 63.7 b$ & $56.3 \pm 7.9 \mathrm{a}$ & $817.5 \pm 42.0 b$ & $116.3 \pm 5.8 \mathrm{a}$ \\
\hline \multirow{2}{*}{ August $21^{\text {st }}, 2013$} & $M$ & $23.2 \pm 2.9 b$ & $4.6 \pm 0.8 \mathrm{a}$ & $14.3 \pm 0.9 b$ & $5.5 \pm 0.5 a$ \\
\hline & A & $1291.1 \pm 40.5 b$ & $35.5 \pm 6.1 \mathrm{a}$ & $799.0 \pm 29.4 b$ & $85.9 \pm 3.1 \mathrm{a}$ \\
\hline \multirow{2}{*}{$\mathrm{SD}^{\mathrm{b}}$} & $M$ & 0.0064 & 0.0001 & 0.0000 & 0.0001 \\
\hline & $A$ & 0.0000 & 0.0530 & 0.0080 & 0.0002 \\
\hline
\end{tabular}

a Letters in columns denote significant differences (LSD test, $p<0.05)$ between treatments on a single sampling date.

${ }^{b} \mathrm{SD}$ - comparison of morning (M) and afternoon $(A)$ recordings between individual sampling dates (Duncan test, $\left.p<0.05\right)$. 
TABLE 2. Apple fruit temperatures $\left({ }^{\circ} \mathrm{C}\right.$ ) on sampling dates 1 (August $8^{\text {th }}, 2013$ ) and 2 (August $21^{\text {st }}, 2013$ ). Morning (M) and afternoon (A) values were recorded on 'Golden Delicious' and 'Braeburn' sunburned apples (SB), healthy sun exposed fruit (HS) and healthy fruit inside the tree crown (IC).

\begin{tabular}{|c|c|c|c|c|c|c|c|}
\hline & \multirow{2}{*}{ Time of day } & \multicolumn{3}{|c|}{ 'Golden Delicious' } & \multicolumn{3}{|c|}{ 'Braeburn' } \\
\hline & & SB & $\mathrm{HS}$ & IC & SB & $\mathrm{HS}$ & IC \\
\hline \multirow[t]{2}{*}{ August $8^{\text {th }}, 2013$} & $M$ & $16.8 \pm 0.3 \mathrm{a}^{\mathrm{a}}$ & $17.0 \pm 0.5 \mathrm{a}$ & $16.2 \pm 0.1 \mathrm{a}$ & $22.6 \pm 0.2 b$ & $22.2 \pm 0.1 \mathrm{ab}$ & $21.9 \pm 0.2 a$ \\
\hline & A & $41.7 \pm 0.8 c$ & $37.2 \pm 0.5 b$ & $34.7 \pm 0.3 a$ & $42.1 \pm 0.8 \mathrm{c}$ & $38.9 \pm 0.8 b$ & $36.8 \pm 0.4 a$ \\
\hline \multirow[t]{2}{*}{ August $21^{\text {st }}, 2013$} & $M$ & $13.2 \pm 0.0 \mathrm{~b}$ & $13.2 \pm 0.0 \mathrm{a}$ & $13.2 \pm 0.0 \mathrm{a}$ & $16.0 \pm 0.5 b$ & $15.8 \pm 0.1 b$ & $15.1 \pm 0.0 \mathrm{a}$ \\
\hline & A & $33.7 \pm 0.6 c$ & $27.1 \pm 0.5 b$ & $24.2 \pm 0.1 \mathrm{a}$ & $33.4 \pm 0.2 \mathrm{c}$ & $28.6 \pm 0.7 b$ & $24.7 \pm 0.1 \mathrm{a}$ \\
\hline \multirow[t]{2}{*}{$T^{b}$} & August $8^{\text {th }}$ & \multicolumn{3}{|c|}{0.0000} & \multicolumn{3}{|c|}{0.0000} \\
\hline & August $21^{\text {st }}$ & \multicolumn{3}{|c|}{0.0000} & \multicolumn{3}{|c|}{0.0000} \\
\hline $\mathrm{SD}^{\mathrm{c}}$ & & \multicolumn{3}{|c|}{0.0118} & \multicolumn{3}{|c|}{0.0002} \\
\hline
\end{tabular}

a Letters in columns denote significant differences (LSD test, $p<0.05)$ between treatments on a single sampling date.

${ }^{\mathrm{b}} \mathrm{TD}$ : time of day - comparison between morning and afternoon temperatures (Duncan test, $p<0.05$ ).

'SD: sampling date - comparison between sampling dates (Duncan test, $p<0.05$ ).

in the morning on both sampling days (Table 2); however, highest temperatures were recorded on sunburned apples (SB), followed by healthy sun exposed apples (HS) and apples inside the tree crown (IC) in the afternoon.

The principal component analysis (PCA) shows the distribution of samples and treatments according to their phenolic content (Figure 1). The comparison was performed between sampling dates and between morning and afternoon samplings (Table 5).

\section{Discussion}

Summer 2013 was the third-warmest summer in the history of temperature measurements in Slovenia (Slovenian Environment Agency). Maximum temperature on SD1 was $40.2^{\circ} \mathrm{C}$ and thus considerably higher than maximum temperature on $\mathrm{SD} 2$, which was $25.8^{\circ} \mathrm{C}$. While air temperature affects all apple fruits in the tree in about the same proportion, the apples located on the periphery of the tree crown are exposed to considerably higher radiation than the apples inside the canopy. Similarly to our results, Jakopic et al. (2009) reported lower radiation inside the tree crown.
Radiation also varied between both sampling days and was considerably higher on August $8^{\text {th }}$ further improving the conditions for sunburn occurrence as reported by Racsko and Schrader (2012).

Ambient air temperature and radiation affected the temperature of apple fruit. Afternoon temperatures recorded on apple fruit on SD1 were approx. $10^{\circ} \mathrm{C}$ higher than afternoon fruit temperatures on SD2. The latter fruit were cooler and less exposed to stress than apples on SD1. Chen et al. (2008) demonstrated that high temperatures damage the oxygen-evolving complex and limit total electron transport to PSII reaction centres.

To minimize the damage induced by harsh weather conditions plants up-regulate the phenolic synthesis and utilize their antioxidant role (Yuri et al., 2010) and their contribution to excessive light screening (Merzlyak et al., 2005). Sunburned apples generally contain higher phenolic levels and are especially abundant in flavonols and dihydrochalcones, (Merzlyak et al., 2002; Felicetti and Schrader, 2009; Yuri et al., 2010; Zupan et al., 2014). In accordance with the reviewed literature, SB accumulated more total flavonols and

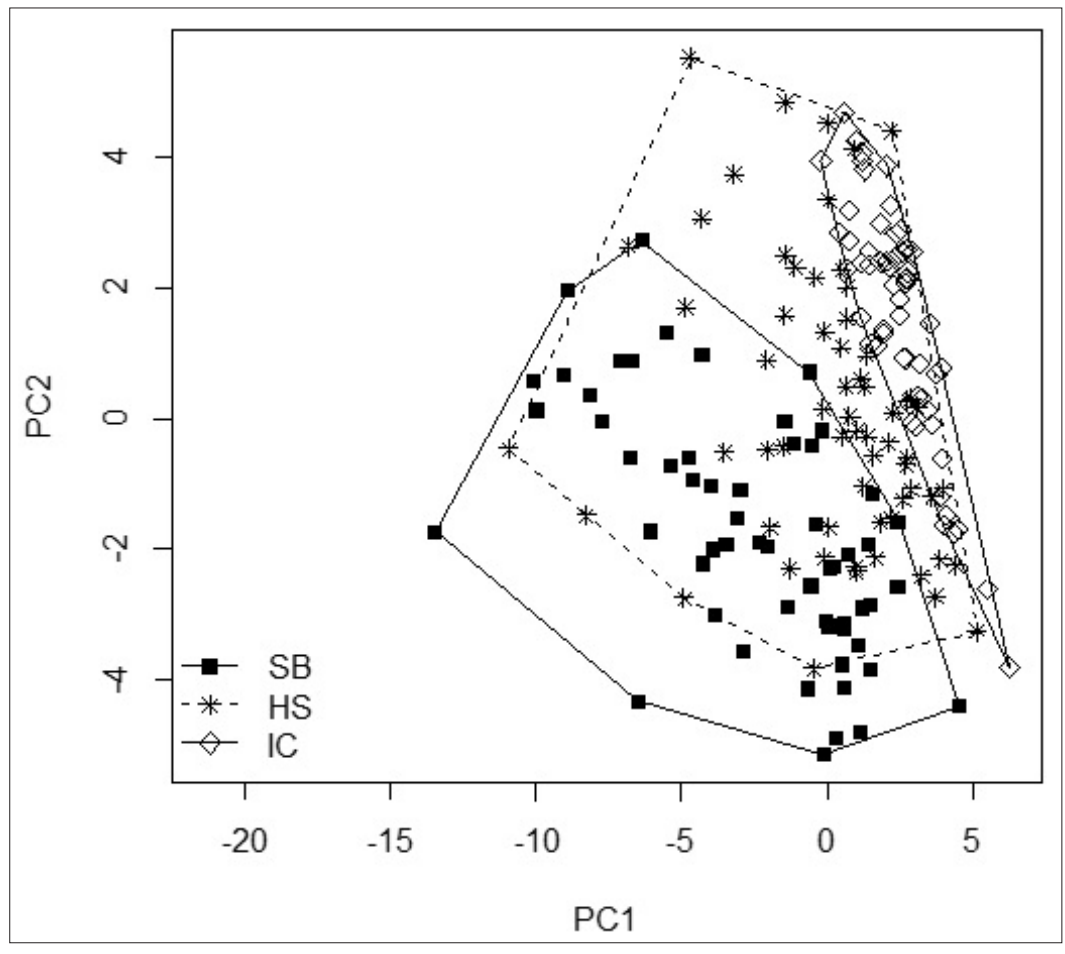

FIGURE 1. PCA diagram of the distribution of samples and treatments according to their phenolic content. 
TABLE 5. Contrasts between sampling dates (SD1-SD2) and contrasts between morning and afternoon samplings (M-A) $(p<0.05)$.

\begin{tabular}{|c|c|c|c|c|c|c|}
\hline & SB & $\mathrm{HS}$ & IC & SB & $\mathrm{HS}$ & IC \\
\hline & SD1-SD2 & SD1-SD2 & SD1-SD2 & $\mathrm{M}-\mathrm{A}$ & $\mathrm{M}-\mathrm{A}$ & $\mathrm{M}-\mathrm{A}$ \\
\hline \multicolumn{7}{|l|}{ 'Braeburn' } \\
\hline Hydroxycinnamic acids & 0.4310 & 0.1986 & 0.1409 & 0.2894 & 0.0207 & 0.1121 \\
\hline Flavanols & 0.1613 & 0.0160 & 0.9252 & 0.4988 & 0.0007 & 0.7413 \\
\hline Dihydrochalcones & 0.0001 & 0.0456 & 0.5890 & 0.4086 & 0.2319 & 0.9996 \\
\hline Flavonols & 0.0194 & 0.7036 & 0.9761 & 0.1595 & 0.1905 & 0.9996 \\
\hline \multicolumn{7}{|l|}{ 'Golden Delicious' } \\
\hline Hydroxycinnamic acids & 0.0000 & 0.0071 & 0.0688 & 0.0008 & 0.8929 & 0.7647 \\
\hline Flavanols & 0.0000 & 0.0000 & 0.0000 & 0.0006 & 0.2301 & 0.9383 \\
\hline Dihydrochalcones & 0.0000 & 0.0000 & 0.0166 & 0.0009 & 0.9810 & 0.9953 \\
\hline Flavonols & 0.0004 & 0.4762 & 0.8277 & 0.0343 & 0.8880 & 0.9991 \\
\hline
\end{tabular}

dihydrochalcones in comparison to IC treatment. Healthy sun-exposed fruit contained moderate levels of these compounds. Phenolic composition of SB and HS apples was less uniform in comparison to IC treatment (Figure 1). Principal component analysis (PCA) based on total phenolic composition exposed the greatest influence of flavonols on the grouping of treatments. PC1 and PC2 explained $64 \%$ of total variability.

Significant differences in the accumulation of all phenolic groups were detected between SB and HS 'Golden Delicious' apples. The contents of all four phenolic groups were higher on SD1, with the exception of flavonols in HS apples. In 'Braeburn' higher levels of flavonols and dihydrochalcones were measured in SB fruits, and more flavanols and dihydrochalcones were detected in HS fruits. Sampling conditions (temperature and radiation) had a minor effect on phenolic composition of 'Golden Delicious' IC apples. Moreover, no differences in phenolic accumulation were detected in 'Braeburn' IC apples between the two sampling dates. This stresses the importance of apple fruit position in the tree canopy in unfavourable weather conditions. Minor variations in apple fruit composition between the two sampling dates may be attributed to developmental changes during apple fruit maturation as fruit were 14 days older on SD2. However, in this period of apple growth, the changes of phenolic contents are rather small (Mayr et al., 1995). Furthermore, the comparison of IC apples between SD1 and SD2 revealed insignificant differences in phenolic composition as opposed to substantial changes detected in exposed fruit. It can therefore be concluded that the changes in fruit phenolic profile can mainly be attributed to different weather conditions.

Can we thus expect alterations in phenolic composition of sun-exposed fruit during the day? Differences in the content of hydroxycinnamic acids and flavanols were detected in HS 'Braeburn' apples sampled in the morning and in the afternoon. A similar pattern was detected in SB 'Golden Delicious' apples, which contained significantly higher levels of all phenolic groups (Table 5). These divergent differences in phenolic contents between the cultivars could be ascribed to their genotype. 'Braeburn' is namely a red and 'Golden Delicious' a yellow cultivar and the latter does not accumulate high levels of anthocyanins. Consequently, on SD2 the first signs of anthocyanin formation were only visible on 'Braeburn' apples. Anthocyanins are known for their protective role against high solar radiation (Solovchenko and Merzlyak, 2008), and thus the mechanism of defence could be different among the two cultivars. Merzlyak et al. (2002) also detected a different response to high sunlight linked to the capability of anthocyanin synthesis of specific apple cultivars. As the first signs of anthocyanin synthesis were only visible on a few apples, we decided not to include them in the analysis, due to such great variability among apples.

To conclude, phenolic content of 'Braeburn' and 'Golden Delicious' apples varied between the two sampling days and moderate fluctuations were also detected during an individual day. Major differences between sampling dates were detected in sun-exposed 'Golden Delicious' apples (SB and HS), which were characterized by higher levels of phenolics on the day with extreme temperatures (SD1). This study is a good basis for further research on the rapid response of apple fruits to stress situations via phenolic accumulation. Further research will incorporate non-destructive methods of phenolic assessment on individual fruits for a longer time period.

\section{Acknowledgments}

This work is part of program Horticulture No. P4-00130481, funded by the Slovenian Research Agency (ARRS).

\section{References}

Akula, R., and Ravishankar, G.A. (2011). Influence of abiotic stress signals on secondary metabolites in plants. Plant Signal. Beh. 6, 1720-1731. https://doi.org/10.4161/psb.6.11.17613.

Awad, M.A., De Jager, A., Van der Plas, L.H.W., and Van der Krol, A.R. (2001). Flavonoid and chlorogenic acid changes in skin of 'Elstar' and 'Jonagold' apples during development and ripening. Sci. Hortic. 90, 69-83. https://doi.org/10.1016/S0304-4238(00)00255-7.

Ayan, A.K., Yanar, P., Cirak, C., and Bilgener, M. (2008). Morphogenetic and diurnal variation of total phenols in some Hypericum species from Turkey during their phenological cycles. Bangladesh J. Botany 36, 8. https://doi.org/10.3329/bjb.v36i1.1547.

Chen, L.S., Li P., and Cheng, L. (2008). Effects of high temperature coupled with high light on the balance between photooxidation and photoprotection in the sun-exposed peel of apple. Planta 228, 745756. https://doi.org/10.1007/s00425-008-0776-3.

Felicetti, D.A., and Schrader, L.E. (2008). Changes in pigment concentrations associated with the degree of sunburn browning of 'Fuji' apple. J. Am. Soc. Hortic. Sci. 133, 27-34. https://doi. org/10.21273/JASHS.133.1.27.

Felicetti, D.A., and Schrader, L.E. (2009). Changes in pigment concentrations associated with sunburn browning of five apple cultivars. II. Phenolics. Plant Sci. 176, 84-89. https://doi. org/10.1016/j.plantsci.2008.09.010. 
Jakopic, J., Stampar, F., and Veberic, R. (2009). The influence of exposure to light on the phenolic content of 'Fuji' apple. Sci. Hortic. 123, 234-239. https://doi.org/10.1016/j.scienta.2009.09.004.

Li, P., Ma, F., and Cheng, L. (2013). Primary and secondary metabolism in the sun-exposed peel and the shaded peel of apple fruit. Physiol. Plantarum 148, 9-24. doi:10.1111/j.1399-3054.2012.01692.x.

Mayr, U., Treutter, D., Santos-Buelga, C., Bauer, H., and Feucht, W. (1995). Developmental changes in the phenol concentrations of 'Golden delicious' apple fruits and leaves. Phytochemistry 38, 11511155. https://doi.org/10.1016/0031-9422(94)00760-Q.

Merzlyak, M.N., Solovchenko, A.E., and Chivkunova, O.B. (2002). Patterns of pigment changes in apple fruits during adaptation to high sunlight and sunscald development. Plant Physiol. Biochem. 40, 679-684. https://doi.org/10.1016/S0981-9428(02)01408-0.

Merzlyak, M.N., Solovchenko, A.E., Smagin, A.I., and Gitelson, A.A. (2005). Apple flavonols during fruit adaptation to solar radiation: spectral features and technique for non-destructive assessment. J. Plant Physiol. 162, 151-160. https://doi.org/10.1016/j. jplph.2004.07.002.

Racsko, J., and Schrader, L.E. (2012). Sunburn of apple fruit: historical background, recent advances and future perspectives. Crit. Rev. Plant Sci. 31, 455-504. doi:10.1080/07352689.2012.696453.

Slatnar, A., Stampar, F., and Veberic, R. (2013). Content of phenolic compounds changes after mechanical injury of apple leaves. PhytonAnn. REI. Bot. 53, 113-124.

Slovenian Environment Agency (2016). http://www.arso.gov.si/en/ (May 2016)

Solovchenko, A.E., and Merzlyak, M.N. (2008). Screening of visible and UV radiation as a photoprotective mechanism in plants. Russian J. Plant Physiol. 55, 719-737. https://doi.org/10.1134/ s1021443708060010.

Treutter, D. (2001). Biosynthesis of phenolic compounds and its regulation in apple. J. Plant Growth Regul. 34, 71-89. doi:10.1023/a:1013378702940.

Yuri, J.A., Neira, A., Quilodran, A., Razmilic, I., Motomura, Y., Torres, C., and Palomo, I. (2010). Sunburn on apples is associated with increases in phenolic compounds and antioxidant activity as a function of the cultivar and areas of the fruit. J. Food Agric. Environ. 8, 920-925.

Zupan, A., Mikulic-Petkovsek, M., Cunja, V., Stampar, F., and Veberic, R. (2013). Comparison of phenolic composition of healthy apple tissues and tissues affected by bitter pit. J. Agric. Food Chem. 61, 12066-12071. https://doi.org/10.1021/jf404087f.

Zupan, A., Mikulic-Petkovsek, M., Slatnar, A., Stampar, F., and Veberic R. (2014). Individual phenolic response and peroxidase activity in peel of differently sun-exposed apples in the period favorable for sunburn occurrence. J. Plant Physiol. 171, 1706-1712. https://doi. org/10.1016/j.jplph.2014.08.010.

Received: Feb. 27, 2018

Accepted: Jan. 26, 2019

Address of authors:

Anka Cebulj*, Maja Mikulic-Petkovsek, Ana Slatnar,

Klemen Eler and Robert Veberič

Department of Agronomy, Biotechnical Faculty, University of Ljubljana, Jamnikarjeva 101, SI-1000 Ljubljana, Slovenia

* Corresponding author; E-mail: anka.cebulj@bf.uni-lj.si

Tel.: +3861320 31 12; Fax: +38614231088 